\title{
Utilization of Psychotropic Medications and Polypharmacy Among Adults in Jazan Region, Saudi Arabia
}

\author{
Abdulkarim M. Meraya1, 2*, Monira Alwhaibi ${ }^{3}$, Mamoon H Syed1, 2, Ali Shwihi², Muath Mashraqi'2, \\ Rina Tripathi' ${ }^{1}$, Yasser Buayti² ${ }^{2}$ and Dhaifallah Moraya ${ }^{2}$ \\ 1. Department of Clinical Pharmacy, College of Pharmacy, Jazan University, Saudi Arabia. \\ 2. Pharmacy Practice Research Unit, College of Pharmacy, Jazan University, Saudi Arabia. \\ 3. Department of Clinical Pharmacy, College of Pharmacy, King Saud University, Riyadh, Saudi Arabia
}

\begin{tabular}{l}
\hline Info Article \\
\hline Submitted: 09-03-2020 \\
Revised: 14-08-2020 \\
Accepted: 01-09-2020 \\
*Corresponding author \\
Abdulkarim M. Meraya \\
Email: \\
ameraya@jazanu.edu.sa
\end{tabular}

\section{INTRODUCTION}

Impaired mental health can encompass chronic mental illnesses (i.e., schizophrenia, posttraumatic stress disorder, depression, anxiety, chronic stress) and other psychological and nervous impairments, such as psychological distress, behavioral disorders, and substance abuse (Herrman et al., 2005). At least $50 \%$ of people in the middle- and high-income countries have a mental

\begin{abstract} disorders, not excluding Saudi Arabia. The availability of newer psychotropic medications has led to increased prescribing and polypharmacy. In Saudi Arabia, exploration of the knowledge gap between the outpatient use of psychotropic medications and the extent of polypharmacy has been scarce in the literature. This study evaluated the prescription pattern of psychotropic medications and the prevalence of psychotropic polypharmacy among adult patients with behavioral/mental illnesses. The study was conducted in the psychiatric outpatient clinics of five hospitals in Jazan Region of Saudi Arabia. A retrospective cross-sectional study was conducted with a non-random sample of adults with behavioral/mental illnesses. Psychotropic polypharmacy was the presence of $\geq 2$ psychotropic medication prescriptions. We conducted multivariable logistic regression models to examine the factors associated with psychotropic polypharmacy. A total of 3.052 adults with a behavioral/mental illness were included in the study. Of these, $74.6 \%$ had antidepressant prescriptions. The second most prescribed drug class was antipsychotics (51.9\%). Furthermore, 65.3\% had psychotropic polypharmacy, and $48.2 \%$ had interclass psychotropic polypharmacy. Adults with anxiety and other mood disorders were less likely to engage in psychotropic polypharmacy and interclass polypharmacy use than those with depression. However, adults with schizophrenia (adjusted odds ratio [AOR]: 1.91; $\mathrm{p}<0.001$ ) were more likely to engage in interclass polypharmacy use than those with depression. Adults with behavioral/mental illnesses in Jazan Region of Saudi Arabia have high rates of antidepressants and antipsychotics use. Additionally, psychotropic polypharmacy is a common prescribing practice, and further evaluation of the safety profile of these combinations is warranted.
\end{abstract}

Keywords. Behavioral/mental illnesses; Drug use evaluation; Electronic health records; Psychotropic polypharmacy. 
medication from the same or different class is very common and often supported by treatment protocols (Trivedi et al., 2006). Nonetheless, prescribing combinations of psychotropic medications that are not supported by clinical trials and therapy guidelines is also common (Karow and Lambert, 2003). Psychotropic polypharmacy refers to the use of $\geq 2$ psychotropic medicines (Costa et al., 2017; Mojtabai and Olfson, 2010; Tapp et al., 2003). Although not all psychotropic polypharmacy is harmful, psychotropic polypharmacy may increase the incidence of adverse drug reactions and drug-drug and drug-disease interactions (Karow and Lambert, 2003; Kukreja et al., 2013). Moreover, psychotropic polypharmacy can lower drug adherence due to the complexity of treatment (Costa et al., 2017). In addition, psychotropic polypharmacy may contribute to avoidable and unnecessary healthcare expenditures (Costa et al., 2017; Kukreja et al., 2013).

Unfortunately, studies on the patterns of psychiatric diagnoses or patterns of psychotropic prescription and polypharmacy in Saudi Arabia are scarce. Alosaimi and others (Alosaimi et al., 2017) examined patterns of psychiatric diagnoses in inpatient and outpatient psychiatric settings at six hospitals in five regions in Saudi Arabia. They found that the most common psychiatric diagnoses among inpatients and outpatients were major depression, schizophrenia, and bipolar disorder (Alosaimi et al., 2017). However, they did not include any hospitals from Jazan Region. Although the prescription of multiple psychotropic medications is associated with adverse drug reactions and drug-drug interactions, no studies have addressed this issue in Saudi Arabia (Karow and Lambert, 2003; Kukreja et al., 2013). Therefore, the specific objectives of the present study are: (1) To evaluate the prescription pattern of psychotropic medications; (2) To evaluate the prevalence of psychotropic polypharmacy $(\geq 2$ psychotropic medications).

\section{MATERIALS AND METHODS Study design}

This study used a non-random, crosssectional study design to evaluate the prescription pattern of psychotropic medications and polypharmacy among adults who visited the outpatient clinics in Jazan Region from January 2018 to March 2018. The prescriptions were screened for the patient's age, sex, diagnosis, and prescribed class of psychotropic medications. We evaluated the extent and profile of psychotropic medication prescriptions among patients in this study sample. We also evaluated the use of the combination of same and different drug classes and the presence $\geq 2$ psychotropic medications in each prescription.

\section{Setting}

Prescriptions from five selected hospitals (one tertiary hospital, three general hospitals, one specialty hospital) in Jazan Region were obtained and processed. These five hospitals were selected based on the availability of complete patient information, and medical and medication history. Data were extracted retrospectively from all prescriptions issued from January 2018 to March 2018 in the psychiatric outpatient clinics of the selected hospitals.

\section{Study sample}

We included the prescriptions of a total of 3,052 adults in the study. The eligibility criteria were based on the dispensing of psychotropic medications, irrespective of duration of use. All prescriptions of adult patients ( $\geq 18$ years) with at least one behavioral/mental illness who were prescribed at least one psychotropic medicine were reviewed and included in the study. Patients with missing information for any parameter (sex, age, diagnosis) were excluded from the study. The flow diagram of the study sample. Adults seeking treatment for epilepsy were also excluded (Figure 1).

\section{Data collection}

Data were obtained from the hospitals' electronic health records and written prescriptions (only one hospital had an electronic health records system). Each patient data from either of the above sources were obtained and evaluated based on the following measures.

\section{Measures}

Outcomes

Psychotropic medications. To evaluate the pattern of psychotropic prescriptions, the following were assessed: (i) antidepressants (ii) antipsychotics (iii) mood stabilizers (iv) sedativehypnotics (v) other psychotropic medications. The list of drugs pertaining to each class are listed in Appendix I. 
Total number of the attendees of the psychiatric outpatient clinics in the selected hospitals from January 2018 to March 2018, N=3,509

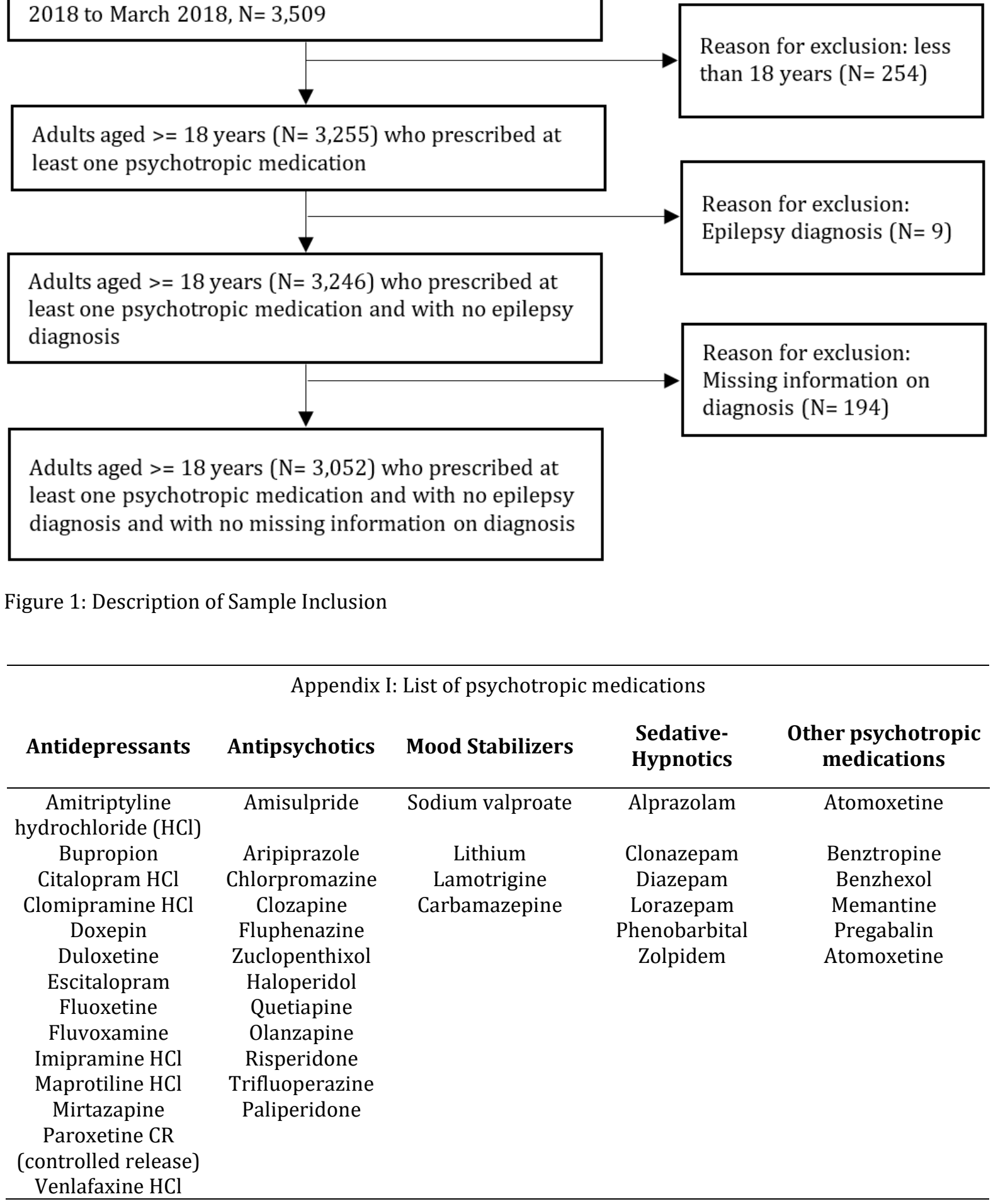


Table I Descriptive Statistics of adults ( $\geq 18$ Years) with behavioral/mental illnesses

\begin{tabular}{|c|c|c|}
\hline & & $\mathrm{N}=3,052$ \\
\hline \multirow[t]{5}{*}{ Age (years) } & & $\mathrm{N}(\%)$ \\
\hline & $18-39$ & $1,160(38 \%)$ \\
\hline & $40-49$ & $757(24.8 \%)$ \\
\hline & $50-59$ & $603(19.8 \%)$ \\
\hline & $>=60$ & $532(17.4 \%)$ \\
\hline \multirow[t]{2}{*}{ Sex } & Men & $1,399(45.8 \%)$ \\
\hline & Women & $1,653(54.2 \%)$ \\
\hline \multirow[t]{9}{*}{ Diagnosis } & Depression & $1,136(37.2 \%)$ \\
\hline & Schizophrenia & $857(28.1 \%)$ \\
\hline & Anxiety & $514(16.8 \%)$ \\
\hline & Mood Disorders & $147(4.8 \%)$ \\
\hline & Intellectual Disability & $122(4 \%)$ \\
\hline & Other Nervous Diseases & $84(2.8 \%)$ \\
\hline & Dementia & $66(2.2 \%)$ \\
\hline & Obsessive Compulsive & $66(2.2 \%)$ \\
\hline & Substance Use & $60(2 \%)$ \\
\hline \multirow[t]{5}{*}{ Hospital } & Hospital 1 & $34(1.1 \%)$ \\
\hline & Hospital 2 & $66(2.2 \%)$ \\
\hline & Hospital 3 & $96(3.1 \%)$ \\
\hline & Hospital 4 & $2,798(91.7 \%)$ \\
\hline & Hospital 5 & $58(1.9 \%)$ \\
\hline \multirow[t]{2}{*}{ Antidepressant Use } & No & $775(25.4 \%)$ \\
\hline & Yes & $2,277(74.6 \%)$ \\
\hline \multirow{2}{*}{ Antipsychotic Use } & No & $1,467(48.1 \%)$ \\
\hline & Yes & $1,585(51.9 \%)$ \\
\hline \multirow[t]{2}{*}{ Mood-Stabilizer Use } & No & $2,937(96.2 \%)$ \\
\hline & Yes & $115(3.8 \%)$ \\
\hline \multirow[t]{2}{*}{ Sedative-Hypnotics Use } & No & $2,936(96.2 \%)$ \\
\hline & Yes & $116(3.8 \%)$ \\
\hline \multirow{2}{*}{ Other Psychotropic Use } & No & $2,563(84 \%)$ \\
\hline & Yes & $489(16 \%)$ \\
\hline \multirow[t]{3}{*}{ Same Class Combinations Use } & Antidepressants & $679(22.2 \%)$ \\
\hline & Antipsychotics & $233(7.6 \%)$ \\
\hline & Sedative-Hypnotics & $3.0(0.1 \%)$ \\
\hline \multirow[t]{10}{*}{ Different Classes Combinations Use } & Antidepressants + Antipsychotics & $957(31.4 \%)$ \\
\hline & Antidepressants + Mood-Stabilizers & $45(1.5 \%)$ \\
\hline & Antidepressants + Sedative-Hypnotics & $68(2.2 \%)$ \\
\hline & Antidepressants + Other Psychotropic & $214(7 \%)$ \\
\hline & Antipsychotics + Mood-Stabilizers & $50(1.6 \%)$ \\
\hline & Antipsychotics + Sedative-Hypnotics & $43(1.4 \%)$ \\
\hline & Antipsychotics + Other Psychotropic & $291(9.5 \%)$ \\
\hline & Sedative-Hypnotics + Mood-Stabilizers & $12(0.4 \%)$ \\
\hline & Sedative-Hypnotics + Other Psychotropic & $15(0.5 \%)$ \\
\hline & Mood-Stabilizers + Other Psychotropic & $12(0.4 \%)$ \\
\hline \multirow[t]{2}{*}{ Any psychotropic polypharmacy } & No & $1,060(34.7 \%)$ \\
\hline & Yes & $1,992(65.3 \%)$ \\
\hline Intra-class Psychotropic & No & $893(29.0 \%)$ \\
\hline Polypharmacy & Yes & $2,159(71.0 \%)$ \\
\hline Interclass Psychotropic & No & $1,580(51.8 \%)$ \\
\hline Polypharmacy & Yes & $1,472(48.2 \%)$ \\
\hline
\end{tabular}


Psychotropic polypharmacy. Here, we use three definitions of psychotropic polypharmacy: 1) receiving prescription of $\geq 2$ psychotropic medications from the same or different class (any polypharmacy); 2) receiving prescription of $\geq 2$ psychotropic medications from the same class (intra-class polypharmacy); 3) receiving prescription of $\geq 2$ psychotropic medications from different classes (interclass polypharmacy). There is no consensus on the number of psychotropic medications above which we could consider the existence of psychotropic polypharmacy. However, defining psychotropic polypharmacy as using $\geq 2$ psychotropic medicines is common in the extant literature (Costa et al., 2017; Mojtabai and Olfson, 2010; Tapp et al., 2003). Both types of polypharmacy were assessed irrespective of duration of use.

\section{Explanatory variables}

We obtained the following data on all adults: age (18-39, 40-49, 50-59, $\geq 60$ years); sex (men, women); hospital setting (five hospitals); and documented behavioral/mental illness diagnosis (i.e., anxiety, dementia, depression, intellectual disability, mood disorders, obsessive compulsive disorders, other nervous diseases, schizophrenia, substance use). These conditions were identified using the International Classifications of Diseases, tenth revision, Clinical Modification (ICD-10-CM) codes. The diagnosis per patient was based on the primary diagnosis presented in the prescription.

\section{Data analysis}

Descriptive analyses, including frequencies and percentages, were calculated for categorical variables. Chi-square tests were computed to examine the relationships between the explanatory variables and the outcomes (any polypharmacy, intra-class polypharmacy and interclass polypharmacy) separately. Multivariable logistic regressions were also conducted to examine the relationships between the explanatory variables and the outcomes separately. In this study, we hypothesized that demographic and clinical factors may affect the prescribing pattern. Therefore, we included age, sex, behavioral/mental illness diagnosis, and hospital setting to all multivariable logistic regression models to determine the adjusted relationship between each one of these variables and the outcomes. In all analyses, we used adults with depression as the reference group, as depression was the most prevalent mental illness. Likewise, we used women and patients in hospital
4 as the reference groups, as they comprised the majority of our sample. However, adults aged $\geq 60$ were used as the reference group in the analyses, as they are associated with high rates of polypharmacy in general. The statistical analyses were performed using Stata 15.0 (Stata Corp LP, College Station, USA).

\section{Ethical considerations}

The Jazan University Institutional Research Review and Ethics Committee (IRREC) reviewed and approved this study and all its procedures (IRREC No. 85959). We ensured that each patient was given an identification number and that all patient data were rendered anonymous to safeguard patient privacy.

\section{RESULTS AND DISCUSSION Description of the study sample}

The study sample consisted of 3,052 adults ( $\geq 18$ years) with a behavioral/mental illness diagnosis. Approximately $46 \%$ of the sample was men and $54 \%$ was women. Most of the patients $(38 \%)$ were young, i.e., between the ages of 18 and 39 years.

In our sample, the most prevalent mental illness was depression (37.2\%), followed by schizophrenia $(28.1 \%)$ and anxiety $(16.8 \%)$. The national prevalence of depression in Saudi Arabia is between $18 \%$ and $41 \%$ (Al-Khathami and Ogbeide, 2002; Al Rashed et al., 2019; Alibrahim et al., 2010). As our finding is closer to the upper limit of prevalence, depression in Jazan Region seems to be higher when compared to the other regions in Saudi Arabia (Al-Qadhi et al., 2014). The prevalence of schizophrenia and anxiety in our study is consistent with the findings of Alosaimi et al., who evaluated the data from the five geographical regions of Saudi Arabia (Alosaimi et al., 2017).

\section{Prescription pattern of psychotropic medications \\ Most of the patients (74.6\%) were} prescribed antidepressants, and $22 \%$ were prescribed combinations of antidepressants. These results indicate that outpatient prescription of antidepressants in Jazan Region is high. This is consistent with the findings of another study by Alosaimi et al., which reported that outpatient treatment with antidepressants was higher when compared to that for inpatients (Alosaimi et al., 2016). Only $37 \%$ of the patients in our sample were diagnosed with depression, which may be indicative of off-label use of antidepressants. 
Table II Unadjusted and Adjusted odds ratios (ORs) for any psychotropic polypharmacy

\begin{tabular}{|c|c|c|c|c|c|c|c|}
\hline & $\begin{array}{c}\text { No polypharmacy } \\
\text { use } \mathrm{N}(\%)\end{array}$ & $\begin{array}{c}\text { Polypharmacy } \\
\text { use N (\%) }\end{array}$ & p- & OR (95\%CI) & $\begin{array}{c}\text { p- } \\
\text { valueb }\end{array}$ & AOR (95\%CI) & $\begin{array}{c}\text { p- } \\
\text { valuec }\end{array}$ \\
\hline Total & $1,060(34.7 \%)$ & $1,992(65.3 \%)$ & & & & & \\
\hline Age (years) & & & 0.100 & & & & \\
\hline$>=60$ & $171(16.13 \%)$ & $361(18.12 \%)$ & & Ref. & Ref. & Ref. & Ref. \\
\hline $18-39$ & 433 (40.85\%) & 727 (36.5\%) & & $0.80(0.64-0.99)$ & 0.039 & $0.76(0.60-0.96)$ & 0.024 \\
\hline $40-49$ & $259(24.43 \%)$ & $498(25 \%)$ & & $0.91(0.72-1.15)$ & 0.438 & $0.86(0.67-1.1)$ & 0.237 \\
\hline $50-59$ & 197 (18.58\%) & $406(20.38 \%)$ & & $0.98(0.76-1.25)$ & 0.850 & $0.91(0.70-1.19)$ & 0.489 \\
\hline Sex & & & $<0.001$ & & & & \\
\hline Men & $438(41.32 \%)$ & $961(48.24 \%)$ & & $1.32(1.14-1.54)$ & $<0.001$ & $1.17(0.99-1.38)$ & 0.07 \\
\hline Women & $622(58.68 \%)$ & $1,031(51.76 \%)$ & & & & Ref. & Ref. \\
\hline Diagnosis & & & $<0.001$ & & & & \\
\hline Anxiety & 223 (21.04\%) & $291(14.61 \%)$ & & $0.62(0.5-0.77)$ & $<0.001$ & $0.64(0.51-0.80)$ & $<0.001$ \\
\hline Dementia & $24(2.26 \%)$ & $42(2.11 \%)$ & & $0.83(0.49-1.39)$ & 0.475 & $0.65(0.38-1.11)$ & 0.118 \\
\hline Depression & $365(34.43 \%)$ & $771(38.7 \%)$ & & Ref. & Ref. & Ref. & Ref. \\
\hline $\begin{array}{l}\text { Intellectual } \\
\text { Disability }\end{array}$ & $54(5.09 \%)$ & $68(3.41 \%)$ & & $0.6(0.41-0.87)$ & 0.007 & $0.60(0.41-0.89)$ & 0.012 \\
\hline Mood Disorders & $75(7.08 \%)$ & $72(3.61 \%)$ & & $0.45(0.32-0.64)$ & $<0.001$ & $0.42(0.29-0.6)$ & $<0.001$ \\
\hline $\begin{array}{l}\text { Obsessive } \\
\text { Compulsive }\end{array}$ & $23(2.17 \%)$ & $43(2.16 \%)$ & & $0.89(0.53-1.49)$ & 0.646 & $0.87(0.51-1.48)$ & 0.605 \\
\hline $\begin{array}{l}\text { Other Nervous } \\
\text { Diseases }\end{array}$ & $43(4.06 \%)$ & $41(2.06 \%)$ & & $0.45(0.29-0.7)$ & $<0.001$ & $0.73(0.44-1.2)$ & 0.213 \\
\hline Schizophrenia & $242(22.83 \%)$ & $615(30.87 \%)$ & & $1.2(0.99-1.46)$ & 0.062 & $1.13(0.92-1.39)$ & 0.247 \\
\hline Substance Use & $11(1.04 \%)$ & $49(2.46 \%)$ & & $2.11(1.08-4.1)$ & 0.028 & $1.81(0.92-3.57)$ & 0.087 \\
\hline Hospital & & & $<0.001$ & & & & \\
\hline Hospital 1 & $23(2.17 \%)$ & $11(0.55 \%)$ & & $0.22(0.11-0.46)$ & $<0.001$ & $0.25(0.12-0.53)$ & $<0.001$ \\
\hline Hospital 2 & $50(4.72 \%)$ & $16(0.8 \%)$ & & $0.15(0.08-0.26)$ & $<0.001$ & $0.15(0.08-0.26)$ & $<0.001$ \\
\hline Hospital 3 & $47(4.43 \%)$ & $49(2.46 \%)$ & & $0.49(0.32-0.73)$ & 0.001 & $0.6(0.39-0.92)$ & 0.020 \\
\hline Hospital 4 & $889(83.87 \%)$ & $1,909(95.83 \%)$ & & Ref. & Ref. & Ref. & Ref. \\
\hline Hospital 5 & $51(4.81 \%)$ & $7(0.35 \%)$ & & $0.06(0.03-0.14)$ & $<0.001$ & $0.06(0.03-0.13)$ & $<0.001$ \\
\hline
\end{tabular}

a: Based on chi $^{2}$ to examine the association between each explanatory variable and any polypharmacy use. b: Based on separate logistic regressions to examine the unadjusted relationships between each explanatory variable and any psychotropic polypharmacyc: Based on multivariable logistic regression to examine the adjusted relationship between each explanatory variable and any polypharmacy use.

The prescribing of off-label antidepressants warrants attention because it imposes unnecessary costs on patients and payers and is associated with notable adverse effects (Hu et al., 2004) and safety concerns., and safety concerns (Coupland et al., 2018; O'neil et al., 2018).

Approximately $52 \%$ of the patients in our study had antipsychotics prescriptions, and $31.4 \%$ had combinations of antidepressants and antipsychotics. A combination of these two classes is common in practice, especially in the treatment of resistant depression, obsessive-compulsive disorders, and schizophrenia (Goodwin et al., 2009). A combination of antidepressants and antipsychotics was superior in the treatment of psychotic depression (Farahani and Correll, 2012), major depression (Nelson and Papakostas, 2009; Spielmans et al., 2013), and schizophrenia (Helfer et al., 2016). Nevertheless, due to the abundance of evidence on the related harms (Helfer et al., 2016; Spielmans et al., 2013), clinicians and health care professionals should weigh the benefits and risks when prescribing antidepressant-antipsychotic co-treatment.

\section{Psychotropic polypharmacy}

Any psychotropic polypharmacy

More than $65 \%$ of the patients had any psychotropic polypharmacy. Table II shows the study sample according to any psychotropic polypharmacy use. The bivariate analysis showed that psychotropic polypharmacy use was 
Table III Unadjusted and Adjusted odds ratios (ORs) for intra-class polypharmacy

\begin{tabular}{|c|c|c|c|c|c|c|c|}
\hline & $\begin{array}{c}\text { No Intra-class } \\
\text { polypharmacy } \\
\mathrm{N}(\%)\end{array}$ & $\begin{array}{c}\text { Intra-class } \\
\text { polypharmacy } \\
\mathrm{N}(\%) \\
\end{array}$ & $\begin{array}{c}\text { p- } \\
\text { value }^{a}\end{array}$ & ORs (95\%CI) & $\begin{array}{c}\text { p- } \\
\text { value }^{b}\end{array}$ & AORs (95\%CI) & $\begin{array}{c}\text { p- } \\
\text { valuec }^{c}\end{array}$ \\
\hline Total & $2,159(71 \%)$ & $893(29 \%)$ & & & & & \\
\hline Age (years) & & & 0.016 & & & & \\
\hline$>=60$ & $393(18.2 \%)$ & 139 (15.57\%) & & Ref. & Ref. & Ref. & Ref. \\
\hline $18-39$ & 843 (39.05\%) & 317 (35.5\%) & & $1.06(0.84-1.34)$ & 0.606 & $1.21(0.95-1.55)$ & 0.125 \\
\hline $40-49$ & 518 (23.99\%) & 239 (26.76\%) & & $1.3(1.02-1.67)$ & 0.035 & $1.32(1.02-1.71)$ & 0.034 \\
\hline $50-59$ & 405 (18.76\%) & 198 (22.17\%) & & 1.38 (1.07-1.79) & 0.014 & $1.26(0.97-1.64)$ & 0.088 \\
\hline Sex & & & 0.029 & & & & \\
\hline Men & 1,017 (47.11\%) & 382 (42.78\%) & & $0.84(0.72-0.98)$ & 0.029 & $0.99(0.83-1.18)$ & 0.934 \\
\hline Women & $1,142(52.89 \%)$ & $511(57.22 \%)$ & & Ref. & Ref. & Ref. & Ref. \\
\hline Diagnosis & & & $<0.001$ & & & & \\
\hline Anxiety & 347 (16.07\%) & $167(18.7 \%)$ & & $0.82(0.66-1.02)$ & 0.073 & $0.87(0.69-1.09)$ & 0.219 \\
\hline Dementia & $56(2.59 \%)$ & $10(1.12 \%)$ & & $0.3(0.15-0.6)$ & 0.001 & $0.32(0.16-0.64)$ & 0.001 \\
\hline Depression & 715 (33.12\%) & $421(47.14 \%)$ & & Ref. & Ref. & Ref. & Ref. \\
\hline $\begin{array}{l}\text { Intellectual } \\
\text { Disability }\end{array}$ & $113(5.23 \%)$ & $9(1.01 \%)$ & & $0.14(0.07-0.27)$ & $<0.001$ & $0.13(0.07-0.27)$ & $<0.001$ \\
\hline Mood Disorders & $114(5.28 \%)$ & $33(3.7 \%)$ & & $0.49(0.33-0.74)$ & 0.001 & $0.45(0.3-0.68)$ & $<0.001$ \\
\hline $\begin{array}{l}\text { Obsessive } \\
\text { Compulsive }\end{array}$ & $40(1.85 \%)$ & $26(2.91 \%)$ & & $1.1(0.66-1.84)$ & 0.703 & $1.02(0.61-1.7)$ & 0.948 \\
\hline $\begin{array}{l}\text { Other Nervous } \\
\text { Diseases }\end{array}$ & $64(2.96 \%)$ & $20(2.24 \%)$ & & $0.53(0.32-0.89)$ & 0.016 & $0.89(0.51-1.55)$ & 0.670 \\
\hline Schizophrenia & 669 (30.99\%) & $188(21.05 \%)$ & & $0.48(0.39-0.58)$ & $<0.001$ & $0.46(0.37-0.57)$ & $<0.001$ \\
\hline Substance Use & $41(1.9 \%)$ & $19(2.13 \%)$ & & $0.79(0.45-1.37)$ & 0.399 & $0.72(0.41-1.28)$ & 0.267 \\
\hline Hospital & & & $<0.001$ & & & & \\
\hline Hospital 1 & $29(1.34 \%)$ & $5(0.56 \%)$ & & $0.39(0.15-1.01)$ & 0.052 & $0.33(0.12-0.87)$ & 0.024 \\
\hline Hospital 2 & $58(2.69 \%)$ & $8(0.9 \%)$ & & $0.31(0.15-0.65)$ & 0.002 & $0.25(0.12-0.53)$ & $<0.001$ \\
\hline Hospital 3 & $81(3.75 \%)$ & $15(1.68 \%)$ & & $0.42(0.24-0.73)$ & 0.002 & $0.36(0.2-0.64)$ & 0.001 \\
\hline Hospital 4 & 1,938 (89.76\%) & $860(96.3 \%)$ & & Ref. & Ref. & Ref. & Ref. \\
\hline Hospital 5 & $53(2.45 \%)$ & $5(0.56 \%)$ & & $0.21(0.08-0.53)$ & 0.001 & $0.2(0.08-0.5)$ & 0.001 \\
\hline
\end{tabular}

a: Based on chi $^{2}$ to examine the association between each explanatory variable and intra-class polypharmacy. b: Based on separate logistic regressions to examine the unadjusted relationships between each explanatory variable and intraclass polypharmacy. c: Based on multivariable logistic regression to examine the adjusted relationship between each explanatory variable and intra-class polypharmacy.

associated with sex, diagnosis, and hospital setting. Table II also showed the logistic regressions model unadjusted odds ratios (ORs) and adjusted ORs (AORs) with their 95\% confidence intervals for polypharmacy use.

In the unadjusted analyses, men were more likely to have psychotropic polypharmacy than women (OR: 1.32; p<0.001). Likewise, patients with substance use (OR: $2.11 ; \mathrm{p}=0.028$ ) were more likely to have any psychotropic polypharmacy.
Nevertheless, patients with anxiety (OR: 0.62 ; $\mathrm{p}<0.001$ ), intellectual disability (OR: 0.60; $\mathrm{p}=0.007$ ), mood disorders (OR: 0.45; $\mathrm{p}<0.001$ ), and other nervous diseases (OR: 0.45 ; $\mathrm{p}<0.001$ ) were less likely to have any psychotropic polypharmacy as compared to their counterparts with depression. In the adjusted analyses, there was no significant relationship between sex and any psychotropic polypharmacy. Conversely, patients with anxiety (AOR: 0.64; $\mathrm{p}<0.001$ ), other mood 
disorders (AOR: 0.42; $\mathrm{p}<0.001$ ), and intellectual disability (AOR: $0.60 ; p=0.012$ ) were less likely to engage in any psychotropic polypharmacy use than those with depression. Nevertheless, there was no statistical difference in any psychotropic polypharmacy use between the patients with depression and those with schizophrenia, dementia, obsessive compulsive disorders, or substance use.

\section{Intra-class psychotropic polypharmacy}

Among the patients in our sample, 29\% had intra-class psychotropic polypharmacy use. Table III shows the study sample according to intra-class psychotropic polypharmacy use. The bivariate analysis shows that intra-class psychotropic polypharmacy use was associated with age, sex, diagnosis, and hospital setting. Intra-class polypharmacy prescriptions were more prevalent among women than men $(57.2 \%$ vs. $42.8 \%)$. Patients with anxiety, schizophrenia, and depression engaged in a significantly higher proportion of intra-class polypharmacy use (18.7\%, 21.0\%, 47.1\%, respectively).

Table III shows the logistic regression ORs and AORs with their $95 \%$ confidence intervals for intra-class polypharmacy use. The unadjusted analyses showed that younger adults (age, 40-59 years) were more likely to have intra-class polypharmacy use than older adults (age, $\geq 60$ years). However, men were less likely to have intraclass psychotropic polypharmacy use than women (OR: 0.84, $p=0.029$ ). Similarly, patients with dementia (OR: 0.3; $\mathrm{p}=0.001$ ), intellectual disability (OR: 14; $\mathrm{p}<0.001$ ), mood disorders (OR: 0.49; $\mathrm{p}=0.001$ ), other nervous diseases (OR: 0.53; $\mathrm{p}=0.016$ ), and schizophrenia (OR: $0.48, \mathrm{p}<0.001$ ) were less likely to have intra-class polypharmacy use than those with depression.

The adjusted analyses showed that there was no significant difference in intra-class polypharmacy use between men and women. Nevertheless, patients with dementia (OR: 0.32; $\mathrm{p}=0.001$ ), intellectual disability (OR: $13 ; \mathrm{p}<0.001$ ), mood disorders (OR: 0.45; $\mathrm{p}<0.001$ ), and schizophrenia (OR: $0.46, \mathrm{p}<0.001)$ were less likely to have intra-class polypharmacy use than those with depression.

\section{Interclass psychotropic polypharmacy}

Table IV shows the study sample according to interclass psychotropic polypharmacy use. The bivariate analysis showed that interclass polypharmacy use was associated with sex, diagnosis, and hospital setting. Interclass polypharmacy use was more prevalent among men than women $(54.0 \%$ vs. $46.0 \%)$. Patients with schizophrenia and depression engaged in a significantly higher proportion of interclass polypharmacy use $(37.2 \%$ and $35.3 \%$, respectively).

Table IV shows the logistic regression model ORs and AORs with their $95 \%$ confidence intervals for interclass polypharmacy use. The results were similar in the unadjusted and adjusted analyses. The adjusted analyses showed that patients with anxiety (AOR: $0.57 ; \mathrm{p}<0.001$ ) and other mood disorders (AOR: $0.56 ; p=0.002$ ) were less likely to engage in interclass polypharmacy use than those with depression. However, patients with schizophrenia (AOR: 1.91; $\mathrm{p}<0.001$ ) and substance use (AOR: 1.75; $p=0.049$ ) were more likely to engage in interclass polypharmacy use than those with depression. It must be noted that polypharmacy use (any use and interclass) varied among hospital settings; moreover, both models were more efficient when hospital setting was included.

Our results indicate that psychotropic polypharmacy is routine practice in Jazan Region. This is consistent with previous studies found that psychotropic polypharmacy rates are high across countries despite the recommendations to avoid such combinations. The prevalence of polypharmacy in psychiatry ranges $13-90 \%$ (Kukreja et al., 2013; Tomasi et al., 2006; Xiang et al., 2016). In the present study, psychotropic polypharmacy was prevalent in more than half of the patients. Similar findings have been reported for Saudi Arabia by Alharbi et al. (Alharbi et al., 2019). Psychotropic polypharmacy can have a deleterious impact by exposing patients to severe adverse events such as falls, disability, and mortality in geriatric patients (Moulis et al., 2015). Psychotropic polypharmacy is also implicated in impairment of cognition and mobility, and this has a positive correlation with the number of psychotropic medications used by the patient, irrespective of the class (Loggia et al., 2020).

In the present study, the association between sex and interclass psychotropic polypharmacy use was statistically significant. The odds of interclass polypharmacy use in men was 1.49 times higher than that in women. This finding is consistent with the results of to a recent study conducted by Alharbi et al. in Saudi Arabia, wherein they found that any psychotropic polypharmacy was also more common in men than in women 
Table IV Unadjusted and Adjusted odds ratios (ORs) for interclass polypharmacy

\begin{tabular}{|c|c|c|c|c|c|c|c|}
\hline & $\begin{array}{c}\text { No Interclass } \\
\text { polypharmacy } \\
\text { N(\%) }\end{array}$ & $\begin{array}{c}\text { Interclass } \\
\text { polypharmacy } \\
\mathrm{N}(\%)\end{array}$ & $\begin{array}{c}\text { p- } \\
\text { value }\end{array}$ & OR $(95 \% \mathrm{CI})$ & $\begin{array}{c}\text { p- } \\
\text { value }^{b}\end{array}$ & AOR (95\%CI) & $\begin{array}{c}\text { p- } \\
\text { value }\end{array}$ \\
\hline Total & $1,580(51.8 \%)$ & $1,472(48.2 \%)$ & & & & & \\
\hline Age (years) & & & 0.092 & & & & \\
\hline$>=60$ & $249(15.76 \%)$ & $283(19.23 \%)$ & & Ref. & Ref. & Ref. & Ref. \\
\hline $18-39$ & 616 (38.99\%) & 544 (36.96\%) & & $0.78(0.63-0.95)$ & 0.016 & $0.66(0.53-0.83)$ & 0.005 \\
\hline $40-49$ & $399(25.25 \%)$ & $358(24.32 \%)$ & & $0.79(0.63-0.99)$ & 0.037 & $0.71(0.56-0.9)$ & 0.059 \\
\hline $50-59$ & $316(20 \%)$ & 287 (19.5\%) & & $0.80(0.63-1.01)$ & 0.060 & $0.79(0.61-1.01)$ & 0.005 \\
\hline Sex & & & $<0.001$ & & & & \\
\hline Men & $604(38.23 \%)$ & 795 (54.01\%) & & $1.90(1.64-2.19)$ & $<0.001$ & $1.49(1.27-1.75)$ & $<0.001$ \\
\hline Women & $976(61.77 \%)$ & 677 (45.99\%) & & Ref. & Ref. & Ref. & Ref. \\
\hline Diagnosis & & & $<0.001$ & & & & \\
\hline Anxiety & $350(22.15 \%)$ & $164(11.14 \%)$ & & $0.56(0.45-0.69)$ & $<0.001$ & $0.57(0.4$ & $<0.001$ \\
\hline Dementia & 27 (1.71\%) & $39(2.65 \%)$ & & $1.71(1.03-2.83)$ & 0.037 & $1.31(0.78-2.21)$ & 0.308 \\
\hline Depression & $616(38.99 \%)$ & $520(35.33 \%)$ & & Ref. & Ref. & Ref. & Ref. \\
\hline $\begin{array}{l}\text { Intellectual } \\
\text { Disability }\end{array}$ & $59(3.73 \%)$ & $63(4.28 \%)$ & & $1.26(0.87-1.84)$ & 0.218 & $1.26(0.85-1.86)$ & 0.248 \\
\hline Mood Disorders & $100(6.33 \%)$ & 47 (3.19\%) & & $0.56(0.39-0.8)$ & 0.002 & $0.56(0.39-0.82)$ & 0.002 \\
\hline $\begin{array}{l}\text { Obsessive } \\
\text { Compulsive }\end{array}$ & $40(2.53 \%)$ & $26(1.77 \%)$ & & $0.77(0.46-1.28)$ & 0.313 & $0.83(0.49-1.38)$ & 0.467 \\
\hline $\begin{array}{l}\text { Other Nervous } \\
\text { Diseases }\end{array}$ & $57(3.61 \%)$ & 27 (1.83\%) & & $0.56(0.35-0.9)$ & 0.017 & $0.67(0.40-1.12)$ & 0.129 \\
\hline Schizophrenia & $310(19.62 \%)$ & 547 (37.16\%) & & $2.09(1.74-2.51)$ & $<0.001$ & $1.91(1.58-2.32)$ & $<0.001$ \\
\hline Substance Use & $21(1.33 \%)$ & $39(2.65 \%)$ & & $2.2(1.28-3.79)$ & 0.004 & $1.75(1.00-3.05)$ & 0.049 \\
\hline Hospital & & & $<0.001$ & & & & \\
\hline Hospital 1 & $26(1.65 \%)$ & $8(0.54 \%)$ & & $0.3(0.14-0.67)$ & 0.003 & $0.39(0.17-0.88)$ & 0.023 \\
\hline Hospital 2 & $56(3.54 \%)$ & $10(0.68 \%)$ & & $0.18(0.09-0.35)$ & $<0.001$ & $0.20(0.10-0.40)$ & $<0.001$ \\
\hline Hospital 3 & $56(3.54 \%)$ & $40(2.72 \%)$ & & $0.7(0.46-1.06)$ & 0.093 & $1.07(0.68-1.67)$ & 0.764 \\
\hline Hospital 4 & 1,387 (87.78\%) & $1,411(95.86 \%)$ & & Ref. & Ref. & Ref. & Ref. \\
\hline Hospital 5 & $55(3.48 \%)$ & $3(0.2 \%)$ & & $0.05(0.02-0.17)$ & $<0.001$ & $0.05(0.01-0.15)$ & $<0.001$ \\
\hline
\end{tabular}

a: Based on chi $^{2}$ to examine the association between each explanatory variable and interclass polypharmacy use. b: Based on separate logistic regressions to examine the unadjusted relationships between each explanatory variable and interclass polypharmacy c: Based on multivariable logistic regression to examine the adjusted relationship between each explanatory variable and interclass polypharmacy use.

(Alharbi et al., 2019). However, no statistical difference was found in any and intra-class psychotropic polypharmacy between men and women. These findings indicate that different results can be obtained with different definitions of psychotropic polypharmacy. It is also possible that cultural and socioeconomic factors may be responsible for these differences, but we were unable to explore them in the present study.

The negative association between psychiatric patients with intellectual disability and polypharmacy in the present study contradicts the findings of Vigod et al. and Tan et al., who found a greater likelihood of polypharmacy/interclass polypharmacy in psychiatric patients with intellectual disability (Lunsky and Modi, 2018;
O'Dwyer et al., 2016; Tan et al., 2015; Vigod et al., 2016). This could be due to the cautious attitude of physicians when prescribing to patients with intellectual disability. Another reason could be the differences in family cohesion and social support between Saudi Arabia and the western world. To the best of our knowledge, we are the first in Saudi Arabia to explore the association between intellectual disability and polypharmacy in patients with psychiatric illnesses.

We are also the first in Saudi Arabia to determine the rate of interclass psychotropic polypharmacy, which was lower than that of any psychotropic polypharmacy. We did not investigate the reasons for the lower rate of interclass polypharmacy. However, our results indicate that 
adults with schizophrenia are more likely to have interclass polypharmacy than those with depression. Schizophrenia is a complex disease, and it is associated with various symptoms and functional limitations (Stroup et al., 2018; Zink et al., 2010). Typically, antipsychotics alone are not adequate for addressing all of the symptoms associated with schizophrenia. Therefore, other classes of psychotropic medications are prescribed (Stroup et al., 2018; Zink et al., 2010). In fact, Stroup et al. found that $70 \%$ of their patients with schizophrenia were prescribed $\geq 2$ different classes of psychotropic medications (Stroup et al., 2018). Unfortunately, the safety of these combinations is not well studied. Additionally, we found that patients with substance use were more likely to have interclass polypharmacy than those with depression. Comorbid psychiatric conditions are common among people with substance use (Iqbal et al., 2019; Kelly and Daley, 2013; Ross and Peselow, 2012). Specifically, $45-70 \%$ of people with substance abuse have an additional psychiatric disorder (Iqbal et al., 2019; Kelly and Daley, 2013; Ross and Peselow, 2012). Therefore, treatment with multiple classes of psychotropic medications is common among people with substance use (Kelly and Daley, 2013).

Jazan Region is the smallest region in Saudi Arabia with a population of 1,533,680 (General Authority for Health Statistics, 2016), 40\% of which lives in rural areas (Mahfouz et al., 2015). For the present study, we included all attendees of psychiatric outpatient clinics in five hospitals (one tertiary hospital, three general hospitals, one specialty hospital). As of 2017, there are 25 hospitals in Jazan Region, of which only two are private (General Authority for Health Statistics, 2017). All psychiatric outpatient clinics of Jazan Region are within the governmental hospitals (General Authority for Health Statistics, 2017). The selected hospitals are across the region and we included the only psychiatric hospital in the region. Therefore, we believe that our results are generalizable to adults with behavioral/mental illness diagnoses who seek mental health treatment in Jazan Region.

\section{Strengths and limitations}

To the best of our knowledge, this is the first study to determine the pattern of psychotropic use and psychotropic polypharmacy in Jazan Region. Furthermore, our sample comprised adults from different hospitals and various regions within Jazan. Additionally, our results can be used as the baseline trend for future studies conducted in Jazan Region. Nevertheless, this study also has several limitations. For example, we used both electronic health data and written prescriptions, which entails the risk of information bias (missing data and incomplete registries). Moreover, we were not able to control for socioeconomic and contextual factors, and other medical conditions that may affect the prescribing pattern of psychotropic medications. We also could not collect data on other, previous, or concurrent psychotropic medication use that were not present in the prescription at the time of data collection. Furthermore, we did not identify harmful polypharmacy use or use that is inconsistent with the guidelines. Finally, we did not measure disease severity, which may affect the pattern of psychotropic polypharmacy use.

\section{CONCLUSION}

Adults with behavioral/mental illnesses in Jazan Region of Saudi Arabia have high rates of antidepressants and antipsychotics use. Psychotropic polypharmacy use is also common in Jazan Region. The lower interclass polypharmacy use in our study may reflect positive prescribing behavior of physicians towards psychiatric patients. Investigating whether psychotropic polypharmacy use is consistent with clinical guidelines is the need of the hour. Additionally, further research is needed to determine other clinical and social factors associated with psychotropic polypharmacy use.

\section{ACKNOWLEDGEMENT}

This research received no specific grant from any funding agency, commercial or not-forprofit sectors.

\section{REFERENCES}

A Farahani, and CU Correll, 2012. Are Antipsychotics or Antidepressants Needed for Psychotic Depression?-A Systematic Review and Meta-Analysis of Trials Comparing Antidepressant or Antipsychotic Monotherapy with Combination Treatment. The Journal of clinical psychiatry, 73(4), 486.

A Karow, and M Lambert, 2003. Polypharmacy in treatment with psychotropic drugs: the underestimated phenomenon. Current Opinion in Psychiatry, 16(6), 713-718.

A Tapp, AE Wood, L Secrest, J Erdmann, L Cubberley, and N Kilzieh, 2003. Combination 
antipsychotic therapy in clinical practice. Psychiatric services, 54(1), 55-59.

AD Al-Khathami, and DO Ogbeide,. 2002. Prevalence of mental illness among Saudi adult primary-care patients in Central Saudi Arabia. Saudi Med J, 23(6), 721-724.

AS Al Rashed, AF Al-Naim, BJ Almulhim, MS Alhaddad, AI Al-Thafar, MJ Alali, AM Aleem, S Kashif., and I. Bougmiza. 2019. Prevalence and associated factors of depression among general population in Al-Ahsa, Kingdom of Saudi Arabia: A community-based survey. Neurology, Psychiatry and Brain Research, 31, 32-36.

B Helfer, MT Samara, M Huhn, E Klupp, C Leucht, Y Zhu, RR Engel, and S Leucht, 2016. Efficacy and safety of antidepressants added to antipsychotics for schizophrenia: a systematic review and meta-analysis. American Journal of Psychiatry, 173(9), 876886.

C Coupland, T Hill, R Morriss, M Moore, A Arthur, and J Hippisley-Cox, 2018. Antidepressant use and risk of adverse outcomes in people aged 20-64 years: cohort study using a primary care database. BMC medicine, 16(1), 36.

CA O'neil, MJ Krauss, J Bettale, A Kessels, E Costantinou, WC Dunagan, and VJ Fraser, 2018. Medications and patient characteristics associated with falling in the hospital. Journal of patient safety, 14(1), 27 33.

F Moulis, G Moulis, L Balardy, S Gérard, S Sourdet, M-E Rougé-Bugat, M Lapeyre-Mestre, J-L Montastruc, Y Rolland, and B Vellas, 2015. Searching for a polypharmacy threshold associated with frailty. Journal of the American Medical Directors Association, 16(3), 259-261.

FD Alosaimi, A Alhabbad, MF Abalhassan, EO Fallata, NM Alzain, MZ Alassiry and BA Haddad, 2016. Patterns of psychotropic medication use in inpatient and outpatient psychiatric settings in Saudi Arabia. Neuropsychiatric disease and treatment, 12, 897.

FD Alosaimi, N Alzain, S Asiri, E Fallata, M Abalhassan, A Qrmli, and A Alhabbad, 2017. Patterns of psychiatric diagnoses in inpatient and outpatient psychiatric settings in Saudi Arabia. Archives of Clinical Psychiatry (São Paulo), 44(3), 77-83.
FF Alharbi, SF Alharbi, SB Salih, and K Al-Surimi 2019. Correlates of Psychotropic Polypharmacy in outpatient psychiatric clinics of two military tertiary hospitals in Saudi Arabia. Journal of Family and Community Medicine, 26(3), 213.

G Goodwin, W Fleischhacker, C Arango, P Baumann, M Davidson, M De Hert, P Falkai, S Kapur, S Leucht, and R Licht, 2009. Advantages and disadvantages of combination treatment with antipsychotics: ECNP Consensus Meeting, March 2008, Nice. European Neuropsychopharmacology, 19(7), 520-532.

G Loggia, E Attoh-Mensah, K Pothier, R Morello, P Lescure, M-L Bocca, C Marcelli, and C Chavoix, 2020. Psychotropic Polypharmacy in Adults 55 Years or Older: A Risk for Impaired Global Cognition, Executive Function, and Mobility. Frontiers in Pharmacology, 10, 1659.

General Authority for Statistics 2017. Annual Statistical Yearbook. viewed 10 November 2016, Available from https://www.stats.gov.sa/en/929-0.

General Authority for Statistics. 2016 Demography Survey. Retrieved 22 Jul from https://www.stats.gov.sa/sites/default/file s/en-demographic-research-2016_2.pdf

H Herrman, S Saxena, R Moodie, and WHO 2005. Promoting mental health: concepts, emerging evidence, practice: a report of the World Health Organization, Department of Mental Health and Substance Abuse in collaboration with the Victorian Health Promotion Foundation and the University of Melbourne.

JC Nelson, and GI Papakostas,. 2009. Atypical antipsychotic augmentation in major depressive disorder: a meta-analysis of placebo-controlled randomized trials. American Journal of Psychiatry, 166(9), 980991.

JdO Costa, MdGB Ceccato, APS Melo, FdA Acurcio, and MDC Guimarães, 2017. Gender differences and psychotropic polypharmacy in psychiatric patients in Brazil: a crosssectional analysis of the PESSOAS Project. Cadernos de saude publica, 33, e00168915.

M O'Dwyer, J Peklar, P McCallion, M McCarron, and MC Henman, 2016. Factors associated with polypharmacy and excessive polypharmacy in older people with intellectual disability differ from the general population: a cross- 
sectional observational nationwide study. BMJ Open, 6(4), e010505.

M Zink, S Englisch, and A Meyer-Lindenberg, 2010. Polypharmacy in schizophrenia. Current opinion in psychiatry, 23(2), 103-111.

MH Trivedi, M Fava, SR Wisniewski, ME Thase, F Quitkin, D Warden, L Ritz, AA Nierenberg, BD Lebowitz, and MM Biggs, 2006. Medication augmentation after the failure of SSRIs for depression. New England Journal of Medicine, 354(12), 1243-1252.

MN Iqbal, CJ Levin, and FR Levin, 2019. Treatment for substance use disorder with co-occurring mental illness. FOCUS, A Journal of the American Psychiatric Association, 17(2), 8897.

MS Mahfouz, B-eE Rahim, YM Solan, AM Makeen, and RM Alsanosy, 2015. Khat chewing habits in the population of the Jazan region, Saudi Arabia: prevalence and associated factors. PloS one, 10(8), e0134545.

OA Alibrahim, N Al-Sadat, and NA Elawad, 2010. Gender and risk of depression in Saudi Arabia, a systematic review and metaanalysis. Journal of Public Health in Africa, $1(1)$.

R Mojtabai, and M Olfson, 2010. National trends in psychotropic medication polypharmacy in office-based psychiatry. Archives of General Psychiatry, 67(1), 26-36.

R Tomasi, GG De, G Santone, AR Picardi, Micciolo, D Semisa, S Fava, and P Group, 2006. The prescription of psychotropic drugs in psychiatric residential facilities: a national survey in Italy. Acta psychiatrica scandinavica, 113(3), 212-223.

RG Frank, RM Conti, and HH Goldman. 2005. Mental health policy and psychotropic drugs. The Milbank Quarterly, 83(2), 271-298.

Ross, S., and Peselow, E. (2012). Co-occurring psychotic and addictive disorders: neurobiology and diagnosis. Clinical neuropharmacology, 35(5), 235-243.

S Kukreja, G Kalra, N Shah, and A Shrivastava, 2013. Polypharmacy in psychiatry: a review. Mens sana monographs, 11(1), 82.

SN Vigod, Y Lunsky, V Cobigo, AS Wilton, Somerton, S., and DP Seitz, 2016. Morbidity and mortality of women and men with intellectual and developmental disabilities newly initiating antipsychotic drugs. BJ Psych open, 2(2), 188-194.

Spielmans, GI., MI Berman, E Linardatos, NZ Rosenlicht, A Perry, and AC Tsai, 2013.
Adjunctive atypical antipsychotic treatment for major depressive disorder: a metaanalysis of depression, quality of life, and safety outcomes. PLoS medicine, 10(3), e1001403.

TM Kelly, and DC Daley, 2013. Integrated treatment of substance use and psychiatric disorders. Social work in public health, 28(3-4), 388406.

TS Stroup, T Gerhard, S Crystal, C Huang, Z Tan, MM Wall, CM Mathai, and M Olfson, 2018. Psychotropic medication use among adults with schizophrenia and schizoaffective disorder in the United States. Psychiatric Services, 69(5), 605-608.

V Patel, D Chisholm, R Parikh, FJ Charlson, L Degenhardt, T Dua, AJ Ferrari, S Hyman, R Laxminarayan, and C Levin, 2016. Addressing the burden of mental, neurological, and substance use disorders: key messages from Disease Control Priorities. The Lancet, 387(10028), 16721685.

W Al-Qadhi, S ur Rahman, MS Ferwana and IA Abdulmajeed. 2014. Adult depression screening in Saudi primary care: prevalence, instrument and cost. BMC psychiatry, 14(1), 190.

X Tan, VD Marshall, R Balkrishnan, I Patel, J Chang, and SR Erickson, 2015. Psychotropic medication adherence among communitybased individuals with developmental disabilities and mental illness. Journal of Mental Health Research in Intellectual Disabilities, 8(1), 1-22.

XH Hu, SA Bull, EM Hunkeler, E Ming, JY Lee, B Fireman, and LE Markson, 2004. Incidence and duration of side effects and those rated as bothersome with selective serotonin reuptake inhibitor treatment for depression: patient report versus physician estimate. The Journal of clinical psychiatry, 65(7), 959965.

Y Lunsky, and M Modi, 2018. Predictors of psychotropic polypharmacy among outpatients with psychiatric disorders and intellectual disability. Psychiatric services, 69(2), 242-246.

Y-T Xiang, G Ungvari, C Correll, $\mathrm{H}$ Chiu, and N Shinfuku, 2016. Trends in the access to and the use of antipsychotic medications and psychotropic co-treatments in Asian patients with schizophrenia. Epidemiology and psychiatric sciences, 25(1), 9-17. 